\title{
IDENTIDADES DE RAÇA, GÊNERO E DE SEXUALIDADE NO ENSINO/APRENDIZAGEM DE LÍNGUA INGLESA: SUGESTÕES DE ATIVIDADES
}

\author{
RACE, GENDER AND SEXUALITY IDENTITIES \\ IN ENGLISH LANGUAGE EDUCATION / \\ LEARNING: SUGGESTED ACTIVITIES
}

Rosana Aparecida Ribeiro de Sene*

Resumo: Este artigo traz reflexões sobre o ensino/aprendizagem da Língua Inglesa como instrumento de questionamento das práticas sociais, com abordagens às identidades de raça, gênero e sexualidade. Objetivando analisar como as/os estudantes podem aprender a Língua Inglesa, e ao mesmo tempo (des)construir as identidades de raça, gênero e de sexualidade, considerando as seguintes perguntas de pesquisa: como a Língua Inglesa pode ser utilizada como instrumento de questionamento para as práticas sociais? E, que tipo de atividades podem ser inseridas, nas aulas de Língua Inglesa, que possam oportunizar a (des)construção das identidades de raça, gênero e de sexualidade? Para isso, utilizo o referencial teórico de Ferreira (2015), Louro (2013), Butler (2010), Melo (2015), Moita Lopes (2003). Abordando a metodologia de pesquisa qualitativa, do tipo etnográfica desenvolvida no ano de 2017 onde a geração de dados ocorreu através de entrevistas de grupo focal, em um Colégio Estadual do Paraná, através da utilização dos vídeos: "Vista minha Pele", "Acorda Raimundo" e "Novamente Homofobia na Escola". Os resultados revelam que as identidades de raça, de gênero e de sexualidade são alvos de racismo, preconceito, machismo e homofobia na sala de aula, vindo a colaborar para o fracasso escolar. Assim, as conclusões apontam para a necessidade de inclusão de tais identidades no currículo escolar, principalmente no processo de ensino/ aprendizagem de Língua Inglesa.

Palavras Chaves: Identidades de raça; Identidades de gênero; Identidades de sexualidade; Língua Inglesa.

\footnotetext{
"Professora de Língua Inglesa da SEED Paraná. Mestre em Estudos da Linguagem UEPG - Universidade Estadual de Ponta Grossa. E-mail: senerosana@gmail.com.
} 
AвSTRACT: This article will reflect about teaching / learning of the English Language as a tool for questioning social practices, with approaches to race, gender and sexuality identities. Aiming to analyze how students can learn the English Language, and at the same time provide (de)construction to the identities of race, gender and sexuality. Considering the following research questions: How can the English Language be used as a questioning tool for social practices? And, what kind of activities can be inserted, in English Language classes, that can give opportunity to (de)construct the race, gender and sexuality identities? For this, I use the theoretical framework of Ferreira (2015), Louro (2013), Butler (2010), Melo (2015), Moita Lopes (2003). Addressing the methodology of qualitative research, ethnographic type developed in the year 2017, where data generation occurred through focus group interviews, in a State School of Paraná, through the use of the videos: "Vista minha Pele", "Acorda Raimundo" and "Novamente Homofobia na Escola". The results show that race, gender and sexuality identities are targets of racism, prejudice, chauvinism and homophobia in the classroom, which also contributes to school failure. Thus, the conclusions point for the need to include such identities in the school curriculum, mainly in the process of teaching / learning English Language.

KEYwords: Race Identities; Gender identities; Sexuality identities; English Language.

\section{INTRODUÇÃO}

Considerando que o inglês é uma das línguas mais utilizadas no mundo pós-moderno/ contemporâneo, e que as pessoas que têm domínio dessa língua têm acesso a bens materiais, culturais e simbólicos, se torna relevante reconhecê-la como um importante instrumento de empoderamento e de questionamento para a prática social. Onde as contribuições sejam vistas como mecanismos importantes na construção de sujeitos sociais críticos, os quais possam ter acesso aos mais variados tipos de informações neste mundo globalizado, uma vez que a língua/gem é o espaço essencial de (re)construção da vida social, pois somos seres do discurso que se re/constroem pela palavra, a qual é a matéria principal das aulas de línguas. (MOITA LOPES, 2012).

Pois o que se deseja, enquanto professoras/es de línguas, é que ocorra o engajamento das/os estudantes no discurso e que elas/eles possam utilizar tais discursos para fazer escolhas éticas sobre o mundo social. Tendo a consciência de refutar qualquer tipo de sofrimento humano, quando se tratar da (des)construção das identidades, as quais estão em constante processo de (trans)formação e de (des)construção o tempo todo (LOURO, 1997; BUTLER, 2010), por isso as identidades não são fixas, não são biológicas, mas são construídas socialmente, historicamente, discursiva e performativamente, se tornando instáveis. Com isso, se torna importante compreender as razões que norteiam algumas identidades a serem incluídas/excluídas na sociedade, principalmente no ambiente escolar. Visto que a escola é um dos principais meios sociais, a qual reflete a inclusão/exclusão das identidades vivenciadas. À vista disto, se torna 
importante (re)pensar o currículo escolar, que deve ser cada vez mais abrangente, para que o sofrimento neste espaço possa ser evitado, tornando-se um ambiente seguro e acolhedor, que contemple o sujeito tanto na sua racionalidade, assim como no aspecto social e histórico.

Neste sentido, este artigo estrutura-se da seguinte maneira: na primeira seção (1.) abordarei sobre a "(Des)construção das identidades raciais, de gênero e de sexualidade. Na segunda seção, (2.) faço a exposição sobre "As Identidades raciais, de gênero e de sexualidade e o ensino/aprendizagem de Língua Inglesa", na terceira seção (3.) descrevo "A geração de dados", na quarta seção (4.), serão expostas "As reações das/os estudantes perante os vídeos: "Vista minha Pele", "Acorda Raimundo", "Novamente Homofobia na Escola”, na quinta seção (5.), apresento algumas: "Sugestões de atividades", e finalmente, na sexta seção (6.), apresento "as considerações finais", em que respondo às perguntas de pesquisa propostas no início deste artigo.

\section{1. (DES)CONSTRUÇÃO DAS IDENTIDADES RACIAIS, DE GÊNERO E DE SEXUALIDADE}

A cada dia, se torna mais complexo vivenciar as identidades, as quais as pessoas assumem com ousadia e determinação de romper com as barreiras e fronteiras, antes não ultrapassadas, mas que agora desestabilizam e questionam muitas das certezas ou dos modos de viver tomados como naturais. Com isso, se faz importante compreender que as identidades não são propriedades dos indivíduos, mas sim construções sociais que foram concebidas pelos padrões de normatividade que nos orientam até hoje, nos quais as posições de privilégios e assimetrias sociais de homens, brancos, heterossexuais são supostamente pensadas como as identidades sólidas, permanentes, de referência confiável (LOURO, 2013), subjugando as demais identidades como "diferentes", e que por isso mereciam ser banidas, excluídas e não representadas.

Assim, é relevante considerar a importância do ambiente escolar, em não promover situações de hierarquização das identidades, uma vez que, as/os estudantes observam e internalizam, principalmente atitudes, ações e reações ocorridas na relação aluna/o-professora/or, aluna/o-aluna/o, e até mesmo professora/or-professora/or. Por isso lidar com as identidades de gênero, de raça e de sexualidade no ambiente escolar não é tarefa fácil. Principalmente porque a criança chega à escola já construída pela família, cabendo à escola legitimar ou recusar, colaborar ou não, para desconstruir ou afirmar certas atitudes de preconceito, racismo, violência, machismo, homofobia e de sexismo nesse local.

Tais questões são ainda muito polêmicas, complexas e desconfortáveis, no contexto brasileiro, vistas ainda como tabus (FERREIRA, 2012) tratadas, na maioria das vezes, de forma essencializadas e estereotipada por algumas pessoas que exercem forte poder na sociedade, principalmente no que se refere ao contexto escolar. Entretanto, a resistência e luta contra 
todo o tipo de hierarquização e poder vem sendo demonstrada (FERREIRA, 2015, MELO; 2015), na tentativa de colaborar para a construção de uma sociedade mais inclusiva, acolhedora e democrática, na qual as diferenças sejam vistas e compreendidas como fonte de enriquecimento social, e não a causa de sofrimento, violência e exclusão. (FERREIRA, 2015; MELO, 2015).

À vista disso, considero gênero como uma construção social e cultural (LOURO; 2007, BUTLER; 2010), a qual incute nas pessoas características específicas de como ser "mulher" e de como ser "homem" na sociedade, se fazendo importante compreender que "homem e masculino podem, com igual facilidade, significar tanto um corpo feminino como um masculino, e mulher e feminino, tanto um corpo masculino como um feminino". (BUTLER, 2010, p. 24). Tal compreensão, ainda não é bem aceita na sociedade, resultando muitas vezes em violência e na tentativa de eliminar os sujeitos que fogem à regra de que foi imposta: feminino obrigatoriamente seja um corpo de mullher, e o masculino obrigatoriamente seja um corpo de homem.

Tudo isso se torna uma questão ainda mais complexa quando pensamos nas questões raciais, as quais são vivenciadas pelas pessoas negras com graves consequências, todos os dias, simplesmente por seus corpos serem negros. Gomes (2005) declara que as raças são construções sociais, políticas e culturais produzidas nas relações sociais e de poder ao longo do processo histórico. E que não significa, de forma alguma, um dado da natureza, pois, é no contexto da cultura que nós aprendemos a enxergar as raças. Isso significa que aprendemos a ver negros e brancos como diferentes na forma como somos educadas/os e socializadas/os, a ponto de que essas ditas diferenças serem introjetadas em nossa forma de ser e ver o outro, na nossa subjetividade, nas relações sociais mais amplas. Ou seja, aprendemos, na cultura e na sociedade, a perceber as diferenças, comparar, a classificar, (hierarquizando as classificações sociais de gênero, de raça e sexualidade) e aprendemos também a tratar as diferenças de forma desigual (MELO, 2015).

Dessa forma, compreendo raça como socialmente e historicamente construída, conforme Ferreira (2012), Gomes (2005) e Melo (2015). E que, quando as pessoas são convidadas a se autoclassificar com relação à raça/etnia, suas decisões estão relacionadas às imagens que já foram construídas para elas, tanto no âmbito social quanto histórico, (FERREIRA, 2012). Portanto, se faz importante construir uma autoestima negra, a qual seja capaz de empoderar-se da sua cor, para transpassar a dolorida barreira do racismo, do preconceito e de estereótipos.

Uma vez que a complexidade das identidades se tornam mais tensas, quando os corpos negros assumem viver a sua sexualidade, a qual não seja a heterossexualidade, tal complexidade vem acompanhada de muita violência e racismo. Carregando o forte estereótipo de que os corpos negros desempenham a heteronormatividade e virilidade, sempre. Pois, no senso comum, homens negros que não desempenham performances discursivas e corporais heterossexuais, podem ser acusados de estarem negando a sua própria origem e contrariando as matrizes hegemônicas desta raça (MELO, 2015). Assim, os homens que se afastam da masculinidade 
hegemônica são considerados diferentes, são apresentados como o “outro”, geralmente experimentam práticas de discriminação ou subordinação (LOURO, 1997), algumas vezes fatais.

Por isso, reforço a importância de um currículo escolar no qual seja planejado o processo de ensino/aprendizagem com o objetivo de atingir as/os estudantes de maneira integral, ou seja, um currículo voltado para a formação científica e humana em que as pessoas sejam construídas para o respeito às diferenças. Neste intuíto, o ensino/aprendizagem de língua inglesa pode se tornar uma boa opção, em que o discurso seja inserido nas aulas como instrumento para as discussões da prática social.

\section{AS IDENTIDADES RACIAIS, DE GÊNERO E DE SEXUALIDADE E O ENSINO/ APRENDIZAGEM DA LÍNGUA INGLESA}

Considerando que a linguagem não é neutra e que nossas práticas discursivas envolvem escolhas (intencionais ou não) ideológicas e políticas, atravessadas por relações de poder, que provocam diferentes efeitos no mundo social (LOURO, 2013; MELO, 2015), é fundamental que se reflita sobre o(s) modo(s) como a linguagem é utilizada em nossas aulas de línguas e nos materiais didáticos adotados (MELO, 2015) no sentido de colaborar, ou não, com a "naturalização de discursos que reforçam e normalizam discursos que podem trazer sofrimentos as/ aos envolvidas/os com o trabalho escolar" (MELO, 2015, p. 72). Esse sofrimento pode encontrar, nas aulas de língua inglesa, um aliado importante de conscientização sobre nossos direitos no mundo, contribuindo na desconstrução de privilégios de certas identidades em relação às demais. Para Pennycook;

os estudos da linguagem e gênero, não é saber como os homens e as mulheres falam diferentemente, como se os homens e mulheres preexistissem a seus usos da linguagem como categorias dadas de identidade, mas, em vez disso, compreender como as pessoas desempenham o gênero com palavras. Isso não quer dizer que constantemente desempenhamos identidades generificadas por meio da linguagem, mas que construímos por meio da linguagem a identidade que ela reivindica ser. É no desempenho que fazemos a diferença. (PENNYCOOK, 2006, p. 81).

Dessa forma, é importante compreender que a linguagem se (trans)forma em verdade pela repetição (MELO, 2015), pela forma recorrente de se apropriar de tais atos de fala e veiculá-los nas conversas cotidianas, vindo a se tornar verdade e a marcar os corpos, assim como afirmado por Pinto (2014),

de enunciados como "menina que fala palavrão é muito feia" ou "esse menino fala muito fino, aposto que é gay e nem sabe" ou "só podia ser 
mulher para falar essas coisas", ou "seja homem, fale direito", na escola ou outros ambientes. Também é preciso politizar as estruturas fixadas em materiais didáticos que reproduzem posições sociais ao fixarem e assim naturalizarem escolhas morfológicas, enunciados como "o cientista fez o experimento" e "a enfermeira atendeu o paciente ", e nunca "a cientista fez o experimento", ou "o enfermeiro atendeu a/o paciente”. Igualmente, é preciso politizar os padrões interacionais em sala de aula, em sala de professoras/es, em reuniões pedagógicas; quem fala? Quem é ouvido? Que falas são referenciadas? Que falas são ironizadas? (PINTO, 2014, p. 118).

Diante de tais reflexões, se faz importante buscar por uma educação que reconheça o papel da língua na construção do mundo social (PINTO, 2014), se fazendo necessário desvincular-se da preocupação de contemplar a língua apenas no seu aspecto gramatical, algumas vezes totalmente fora da realidade das/os estudantes, pois quando uma/um estudante não consegue se encontrar no mundo social descrito pelos professores é como se a sua vida não existisse. Por isso, se torna difícil, muitas vezes, transpassar a barreira do preconceito e estereótipos construídos para algumas identidades, em que a linguagem hegemônica é construída e petrificada sob alguns conceitos; "a ponto de dizermos "os homens" para designar os seres humanos” (BEAUVOIR, 1970), ou ainda, sob a ótica de uso correto da gramática, onde utilizamos o masculino para referir-se a várias pessoas, se dentre essas estiver presente um corpo masculino, demonstra o quanto a linguagem colabora, institui e demarca os lugares dos gêneros, não apenas pelo ocultamento do feminino, mas também pela escolha de adjetivos para diferenciar o feminino do masculino, pelo uso (ou não) do diminutivo, pela escolha dos verbos, pelas associações e pelas analogias feitas entre determinadas qualidades, atributos ou comportamentos descritos, principalmente as identidades raciais, de gênero e de sexualidade.

Diante disso, nossas práticas discursivas envolvem escolhas que têm impactos diferenciados no mundo social e nele interferem de forma variada, haja vista que, ao referir-se a meninas e a meninos, ou a homens e a mulheres, sempre na forma masculina, independente da proporção numérica, por mais que não pareça ser um ato inofensivo, na prática acaba por colaborar em reforçar a "superioridade" de um gênero sobre o outro, invisibilizando a menina, a garota, a mulher, a idosa (FURLANI, 2013), dando mais visibilidade ao masculino. Dessa forma, "a linguagem não apenas expressa relações, poderes, lugares, ela os institui, ela não apenas veicula, mas ela produz e pretende fixar diferenças" (LOURO, 1997, p. 65) entre as pessoas, excluindo e demarcando, quase sempre de forma muito "natural", quase imperceptível, mas impositiva e repetitiva. Dessa maneira, Furlani (2013) sugere que tanto na forma verbal como na escrita, em qualquer nível de ensino, é bom:

evitar o tratamento exclusivo no masculino, bem como atentar-se para a linguagem presente nos livros didáticos que costumeiramente o fazem. 
Há muitas alternativas para se evitar usar "homem”... sugiro, "as pessoas", ou, simplesmente, "os homens e as mulheres", "as meninas e os meninos", "os professores e as professoras". E como mudar o nome da espécie parece ser o mais difícil, é possível usar também a espécie humana ou a humanidade. (FURLANI, 2013, p. 73).

Assim, criamos possibilidades para que mulheres, homens, negras/os, gays, lésbicas, travestis, transexuais, bissexuais e demais identidades sejam incluídas na sociedade, principalmente no ambiente escolar.

Por isso, nós professoras/es de línguas não podemos nos limitar a ensinar apenas a língua pela língua, muito pelo contrário, temos que nos propor a dialogar com o mundo contemporâneo, com as práticas sociais que as pessoas vivem. Dessa forma, é preciso questionar os discursos que, muitas vezes, estão cristalizados sobre as identidades, principalmente no que se refere às identidades de raça, de gênero e de sexualidade. Conforme Melo (2015), quando não tratamos, não questionamos os estereótipos de raça, gênero, sexualidade em nossas aulas de língua, na concepção performativa da linguagem, nós acabamos desconsiderando que a linguagem também fere (MELO, 2015), e que às vezes acabamos minimizando as brincadeiras, os apelidos, as piadas, ao utilizar o discurso de que "somos todas/os iguais", sendo que nossas/ os estudantes percebem que, nas práticas sociais, não somos construídas/os todas/os iguais.

Dessa maneira, é preciso compreender que as pessoas usam a linguagem a partir de suas marcas sócio-históricas como homens, mulheres, homoeróticos, heterossexuais, ao mesmo tempo que, nessas práticas, se (re)constroem ao agirem uns em relação aos outros via linguagem (MOITA LOPES, 2003). Visto que "aprendemos a ser quem somos nos encontros interacionais de todo dia” (MOITA LOPES, 2003, p. 27), pois agimos no mundo social por meio da linguagem (MOITA LOPES, 2003), e que ao "enunciarmos, algo é realizado" (MELO, 2015, p. 78). Assim, considero que a linguagem é ação (MELO, 2015), e que somos seres do discurso que se (re)constroem pela palavra, a qual é a matéria principal das aulas de língua, a qual pode ser utilizada para refutar qualquer tipo de sofrimento humano, principalmente na sala de aula de língua inglesa.

Dessa maneira, uma educação cidadã e inclusiva se constrói também nas aulas de língua inglesa, que podem se constituir em um espaço para problematizar temas de raça, de gênero, e de sexualidade e outros temas de relevância social, com o intuito de superar o que nos perturba e nos exclui, tanto no ambiente escolar como na sociedade. 


\section{GERAÇÃO DE DADOS}

O presente artigo $^{1}$ traz resultados parciais de uma pesquisa de Mestrado, desenvolvida em uma Escola Estadual do Paraná, em uma turma de Ensino Médio, utilizando os seguintes instrumentos de geração de dados: questionário, narrativa autobiográfica e entrevista de grupo focal. No entanto, neste artigo será utilizado para análises apenas o instrumento de geração de dados de entrevista de grupo focal, o qual foi organizado conforme a resposta dada para a pergunta: "Qual a sua cor?”

A pergunta, referente à cor/raça colocada no questionário, foi elaborada com base nas informações que o Instituto Brasileiro de Geografia e Estatística (IBGE) menciona a respeito da cor/raça na qual as pessoas se reconhecem. Esta pergunta trouxe as raças/cores: preta/o, parda/o, branca/o, amarela/o, indígena/o, em opção de múltipla-escolha, trazendo, entre parênteses, a explicação de que as cores/raças; preta/o e parda/o; se referem ao pertencimento negra/o, afim de evitar qualquer tipo de dúvida em relação ao pertencimento "negro" o que ainda causa desconforto e nos remete ao racismo, aos ranços da escravização e às imagens que construímos sobre "ser negro" e "ser branco" em nosso país (GOMES, 2005).

Após a turma responder ao questionário, foi solicitado que a turma entrasse em um consenso, indicando 2 alunas negras/pardas, 2 alunas brancas, assim como também 2 alunos negros/pardos, e 2 alunos brancos, totalizando 8 participantes. Considerando a disponibilidade e a vontade em participar de 3 encontros, no horário de contra turno na escola, onde em cada encontro seria abordado um tema referente às identidades de raça, de gênero e de sexualidade.

A partir disso, realizamos 3 encontros para desenvolver as entrevistas de grupo focal, tendo a seguinte organização: para o tema de raça, o vídeo - "Vista minha Pele"; para o tema de gênero, o vídeo - "Acorda Raimundo"; e para o tema de sexualidade, o vídeo - "Novamente Homofobia na Escola”. Para cada encontro, a pesquisadora levou 10 perguntas pré-elaboradas sobre cada um dos temas, com o intuito de direcionar as discussões. Assim, prossegue o resultado das análises obtidas pela geração de dados.

\section{REAÇÕES DAS/OS ESTUDANTES PERANTE OS VÍDEOS "VISTA MINHA PELE”, “ACORDA RAIMUNDO", "NOVAMENTE HOMOFOBIA NA ESCOLA”.}

Neste contexto, menciono as reações das/os estudantes, participantes da pesquisa, perante o vídeo "Vista minha Pele"² o qual provocou impacto nas/os estudantes, em se "imaginar"

\footnotetext{
${ }^{1}$ Dissertação de Mestrado intitulada "Identidades de Raça, de Gênero e de Sexualidade nas aulas de Língua Inglesa na visão das/os estudantes”, (SENE, 2017). UEPG - Universidade Estadual de Ponta Grossa. Mestrado em Estudos da Linguagem. https://tede2.uepg.br/jspui/handle/prefix/1488.

${ }^{2} \mathrm{O}$ vídeo tem a duração de 25 min., foi lançado em 2003, e conta a história de uma garota chamada Maria, a qual que sofre racismo na escola. O racismo ocorre porque ela é branca, e todas as pessoas que se encontram nesta escola são negras. Maria tem uma melhor amiga negra chamada Luana que, ajuda Maria a tentar vencer o racismo. Na escola, ha-
} 
no lugar de negras/os, sofrendo racismo e preconceito no ambiente escolar. A exibição do vídeo provocou espanto e surpresa ao perceberem que o racismo ocorria contra uma garota branca;

nossa que esquisito, ela é branca, (ENTREVISTA de GRUPO FOCAL, TEMA RAÇA, 21/06/16, BETO, BRANCO, 15 ANOS,).

nunca tinha visto um vídeo assim, com gente branca sofrendo racismo ao contrário, é bem diferente mesmo, (ENTREVISTA de GRUPO FOCAL, TEMA RAÇA, 21/06/16, MARIA, BRANCA, 15 ANOS,).

Essas declarações relevam a importância de práticas pedagógicas que sensibilizem e contribuam com a educação de alunas/os no ambiente escolar, as/os quais possam tornar-se pensadoras/es críticas/os (FERREIRA, 2012) ao observarem tais questões. Dessa forma, a sala de aula de língua estrangeira se transformará em um espaço de reflexão sobre as construções culturais das "verdades" que circulam na sociedade, a respeito de raça, gênero e de sexualidade, conforme revelação das/os entrevistadas/os;

Professora pesquisadora: pensando no título do vídeo o que vem à cabeça de vocês?

Alexia (parda, 15 anos): $\quad$ Pra gente se pôr no lugar do negro.

Professora pesquisadora: E, se colocando no lugar do negro, a gente pode ir um pouco mais além do discurso, de que somos todos iguais, ou não tem diferença de cor?

Maria (branca, 15 anos): Tem diferença de cor. A gente fala assim que somos todos iguais, que não dá pra ligar para o que os outros falam, mas se a gente se colocar no lugar do negro, pensando por tudo o que ele passou, pensando em tudo o que os outros podiam falar pra gente, a gente se colocando lá no passado, o negro apanhando nas senzalas e tudo mais, claro que existe diferença, até hoje existe diferença, esse "somos todos iguais" (faz as aspas com a mão) é só perante a Deus mesmo, por que perante ao olhar dos homens a gente não é tudo igual, nunca.

Professora pesquisadora: O que mais chamou atenção no vídeo?

verá eleição para escolher a Miss Festa Junina daquele ano, e Maria quer participar. No entanto, tem uma garota na sua escola, chamada Sueli, que é negra e por quem todos os meninos se encantam. Sueli sempre vence, todo ano, o concurso de Miss Junina da escola, sendo difícil para Maria vencê-la. No entanto, Luana se dispõe a ajudá-la vendendo os votos de Miss Festa Junina. Depois de um tempo, várias pessoas começam a apoiar Maria para o concurso. E Maria começa a se sentir mais segura para participar. Porém, Sueli se irrita com a concorrência e rasga, amassa todos os cartazes que Maria colocou nas paredes como propaganda para a sua candidatura de Miss Festa Junina da escola. No dia da eleição, Maria ganhou vários votos, assim como Sueli. O vídeo não apresenta qual das duas garotas ganhou o concurso, mas apresenta Maria chamando a/o telespectadora/or a fazer uma reflexão sobre o racismo, principalmente no ambiente escolar. Link para acessar o vídeo: https://www.youtube.com/watch?v=LWBodKwuHCM 
Beto (branco, 15 anos): A menina branca fazer trancinha no cabelo pra ficar igual à menina negra,

Dheni (parda, 16 anos): Da um impacto na gente de você se enxergar no lugar do outro, de se enxergar no lugar do negro, (ENTREVISTA de GRUPO FOCAL, TEMA RAÇA, 21/06/16).

Por meio do discurso das/os estudantes, percebi que o vídeo provocou reflexões importantes. Pois, quando foi feita a pergunta: "Pensando no título do vídeo, o que vem à cabeça de vocês"? Imediatamente a estudante Alexia respondeu: "Pra gente se pôr no lugar do negro", confirmando a relevância de incluir nas aulas de língua estrangeira temas do mundo social, onde elas/eles possam ter a oportunidade de "se ver no lugar da outra pessoa", pois na escola aprendemos muito mais do que somente conteúdos e saberes, aprendemos também valores, crenças, hábitos e também a incluir e/ou excluir pessoas. Quando a professora mencionou a próxima pergunta: "E, se colocando no lugar do negro, a gente pode ir um pouco mais além do discurso de que somos todos iguais, ou não tem diferença de cor"? A estudante Maria respondeu que "tem diferença de cor. A gente fala assim que somos todos iguais, que não dá pra ligar para o que os outros falam, mas se a gente se colocar no lugar do negro.... existe diferença, esse "somos todos iguais" é só perante a Deus mesmo, por que perante ao olhar dos homens a gente não é tudo igual, nunca».

Dessa forma, se torna significativo pensar a respeito dos tipos de discursos sobre os corpos negros que têm circulado nas salas de aulas e intervir, uma vez que noções de uniformidade e de homogeneidade continuam sendo estabelecidas nas práticas educacionais. Quando Beto responde à pergunta da professora: "O que mais chamou atenção no vídeo"?, dizendo que foi a questão da "menina branca fazer trancinha no cabelo pra ficar igual à menina negra", nos possibilita compreender relações de identidade e diferença, nas quais a construção da identidade é tanto simbólica quanto social. Em que as trancinhas são vistas como elementos de construção da identidade negra e, portanto, não poderiam ser utilizadas por pessoas brancas, por que a identidade branca se distingue por aquilo que a identidade negra não é, e vice-versa. Ou seja, os símbolos de identidade negra não podem ser os mesmos utilizados para representar a identidade branca, que é considerada como norma. Dessa maneira, a identidade é marcada pela diferença, a qual é sustentada pela exclusão. As discussões prosseguem, provocando as/ os participantes sobre o vídeo assistido:

Professora pesquisadora: E se acontecesse exatamente o que aconteceu no vídeo, o branco sofresse preconceito, vocês acham que haveria algum aprendizado? Iria mudar alguma coisa?

Roger (pardo, 16 anos): Acho que sim.

Alexia (parda, 15 anos): Um pouco, né. 
Roger (pardo, 16 anos): Bastante né, que daí eles iriam ver que não é bom você levar essas brincadeirinhas pra tua casa, porque tem negro que até agride o branco, por causa de brincadeira. Daí eles iriam ver como o negro se sente ofendido, (ENTREVISTA de GRUPO FOCAL, TEMA RAÇA, 21/06/16).

Por meio de tais reflexões, se torna possível perceber que as/os estudantes acreditam que situações de "se colocar no lugar do outro" podem oferecer grandes contribuições para (re) pensar o racismo e o preconceito racial. Principalmente quando o estudante Roger mencionou em seu discurso o pronome "você", seguido do pronome possessivo "tua" e do substantivo "casa", em uma tentativa de chamar atenção das/os colegas que ouvem seu discurso, para que elas/eles se imaginem como vítimas das brincadeiras ofensivas, com as quais ele (con) vive e que aprendeu a revidar. E de como se torna desconfortável ter que aturar as brincadeiras ofensivas em relação à raça, mencionando que "tem negro que até agride o branco, por causa de brincadeira. Daí eles iriam ver como o negro se sente ofendido". Tais afirmativas demonstram que nós professoras/es precisamos utilizar nossas abordagens de ensino para ajudar nossas/os estudantes a encontrarem suas próprias soluções para ajudar na redução das injustiças atuais da sociedade.

Perante o vídeo "Acorda Raimundo"3, relacionado as questões de "gênero", as/os estudantes demonstraram muito estranhamento ao constatar, no vídeo, a mulher ocupando lugares vistos como "somente para os homens", e os homens desempenhando os afazeres domésticos, e cuidando das/os filhas/os, ou seja, "os homens fazendo coisas de mulheres". Mas foi curioso e preocupante quando as/os estudantes mencionaram, a respeito da cena de violência doméstica apresentado no vídeo, que é "normal" tal violência contra as mulheres. Tais discursos das entrevistadas/os nos chamam para a responsabilidade de discutir e refletir sobre o que a sociedade considera como "normal" para mulheres e homens, e qual é o papel social para mulheres e homens? Por que o espanto quando mulheres/homens desempenham papéis que a sociedade não espera que elas/eles desempenhem? Conforme as/os entrevistadas/ os, tais situações merecem discussões;

\footnotetext{
${ }^{3} \mathrm{O}$ vídeo tem a duração de 16 min., foi lançado em 1990, trazendo a história de uma família operária, representada pela personagem Marta e pelo personagem Raimundo, que representam os conflitos familiares e o machismo vividos num mundo onde tudo acontece ao contrário. Raimundo é um dono de casa, grávido, que vive oprimido por sua mulher Marta. Ela trabalha fora enquanto ele toma conta das crianças e da casa. Numa situação inversa, reproduz a relação machista comum entre as famílias de trabalhadores brasileiros. Baseado na radionovela de José Ignácio Lopez Vigil, o vídeo mostra a mulher chegando em casa tarde, depois de tomar umas cervejas com as amigas de trabalho. Enfatiza a dificuldade do dono de casa para conseguir, com a mulher, uns trocados para o mercado e para as necessidades das crianças. Com a participação de José Mayer (outro dono de casa) e de Zezé Motta (outra trabalhadora), o vídeo apresenta a realidade cotidiana de forma invertida entre os sexos. Para os homens, essa situação é apresentada como um verdadeiro pesadelo. Um pesadelo do qual homens e mulheres devem acordar. Link para acessar o vídeo: https://www.youtube. com/watch?v=HvQaqcYQyxU
} 
Professora pesquisadora: O que vocês acharam do vídeo?

Respondem juntas/os: Interessante, (risos).

Professora pesquisadora: Por quê?

Roger (pardo, 16 anos): O homem no lugar da mulher é estranho, vendo deste tipo.

Professora pesquisadora: Estranho, por quê?

Beto (branco, 15 anos): $\quad$ Porque vê a mulher mandando em tudo é estranho. É comum vê diferente.

Alexia (parda, 15 anos): É comum vê a mulher submissa ao homem, cuidando dos filhos, dependente, é isso?

Dheni (parda, 16 anos): É, acho que o homem não aceita esta situação, de se vê no lugar da mulher. Os meninos, que viram o vídeo podem pensar que é um exagero, pensando que a mulher é bem tratada, mas não é. Daí, quando o homem se vê no lugar da mulher, daí ele pensa. Daí se vê como uma situação estranha. Mas daí, quando a gente vê a mulher sofrendo, a gente pensa, ah! Mas a mulher nasceu pra isso. Todo mundo acha, que a mulher nasceu pra ter filho, pra cozinhar, pra fazer de tudo pro marido, pra depender do marido financeiramente. (ENTREVISTA de GRUPO FOCAL, TEMA GÊNERO, 22/06/16).

Os risos ocorreram principalmente diante de algumas cenas do vídeo, como o momento em que a personagem Marta se encontra no bar com as suas amigas para conversar e tomar umas cervejas depois do horário de trabalho. Essa cena provocou uma reação de estranhamento nas/os participantes, sendo reforçada pela resposta de Roger, que mencionou que "o homem no lugar da mulher é estranho", e logo em seguida Beto reafirmou a resposta dada pelo colega, argumentando que "vê a mulher mandando em tudo é estranho", no entanto a resposta é complementada por Dheni, a qual afirma que; "quando o homem se vê no lugar da mulher, daí ele pensa. Daí se vê como uma situação estranha. Mas daí, quando a gente vê a mulher sofrendo, a gente pensa, ah! Mas a mulher nasceu pra isso. Todo mundo acha, que a mulher nasceu pra ter filho, pra cozinhar, pra fazer de tudo pro marido, pra depender do marido financeiramente", tais argumentos demostram que a sociedade atribuí o trabalho doméstico e o cuidado com as/os filhas/os às mulheres e o espaço público como atribuição aos homens. Mesmo as mulheres tendo conseguido conquistar alguns espaços públicos, tal conquista não faz delas mulheres livres do que seja "imposto a elas". Ainda há algumas barreiras das quais as mulheres lutam para se libertar.

Assim, diante do exposto, se faz importante, mais uma vez, reafirmar a importância da língua estrangeira em proporcionar, nas aulas de língua inglesa, temas relevantes socialmente, no qual as/os estudantes possam refletir sobre suas próprias condições enquanto mulheres e homens que desempenham suas funções sociais na sociedade. Se fazendo necessário compreender que "não há nada de biológico nem de natural que explique a subordinação das 
mulheres" (GARCIA, 2011, p. 82), ou seja, o que ocorre é que a ideia de que "a mulher nasceu pra isso[...], que a mulher nasceu pra ter filho, pra cozinhar, pra fazer de tudo pro marido [...] não são ideias naturais e essenciais, mas são construídas por um conjunto de elementos sociais, que de tanto serem repetidas pela sociedade, tornam-se verdades, naturalizando tais imposições. Ou seja, a crença de que mulheres e homens sejam biologicamente distintos serve para justificar a desigualdade social existentes entre ambos (BEAUVOIR, 1970; LOURO, 1997), sendo que os homens possuem privilégios em relação às mulheres. Nestes termos, se faz necessário (re)pensar as condições sociais de mulheres e homens para que as/os estudantes se reconheçam enquanto seres sociais, desconstruindo estereótipos de gênero causadores de sofrimento e destruição da convivência humana.

Em relação ao vídeo "Novamente Homofobia na Escola"4 a reação das/os entrevistadas/ os foi de perplexidade e silenciamento. Tais reações revelam a tomada de consciência das/os estudantes ao se deparar com as demais sexualidades, além da sexualidade heterossexual no ambiente escolar, uma vez que, questões relacionadas à sexualidade ainda são vistas como tabu, ainda mais para serem discutidas na sala de aula. A vista disso, ao terminar o vídeo, em que a professora perguntou: “o que acharam do vídeo?”, o silêncio tomou conta da sala, e ninguém respondeu. Neste momento podemos constatar a desestabilização de algumas certezas trazidas até então, sem nunca serem questionadas, e que a partir deste momento passaram a ser questionadas, dentro do ambiente escolar. Tais indagações provocaram as/os entrevistadas/os a rever certos conceitos, a (re)pensar naquilo que acreditavam como "verdades cristalizadas", e que a partir da troca do discurso se depararam com outras maneiras de relacionamentos, além daquela já conhecida e vista como a "única” maneira correta de se relacionar.

Tudo isso causa impacto e surpresa por que os padrões defendidos pela escola passam a ser questionados dentro da própria instituição. Se tornando perturbadores (LOURO, 2013) e transgressivos tais questionamentos sobre a sexualidade no ambiente escolar, em que a sociedade considera que as pessoas que fogem da hegemonia branca, masculina, heterossexual e cristã, sejam nomeadas como diferentes (LOURO, 1997) e a diferença é sustentada pela exclusão. Dessa forma, pode-se considerar que o vídeo "Novamente Homofobia na Escola" foi perturbador e transgressivo, conforme o fragmento a seguir:

$\begin{array}{ll}\text { Professora pesquisadora: } & \text { O que acharam do vídeo? } \\ \text { Todas/os as/os estudantes: } & \text { Silêncio. } \\ \text { Professora pesquisadora: } & \text { E, aí, o que acharam do vídeo? O que entenderam? }\end{array}$

${ }^{4}$ Este vídeo foi uma produção da UFRJ em parceria com o Grupo Arco-Íris, e exibe os dois polos opostos que se chocam: uma escola, dois casais; um casal hétero, outro casal homo. Para cada casal, a escola reserva um tratamento diferente. $\mathrm{O}$ cotidiano de dois jovens estudantes revela a mistura de homofobia e preconceito, onde para um estudante (;) é somente (;) e, para o outro, opressão diária. Este vídeo foi produzido a partir de uma oficina realizada pelo Projeto Diversidade Sexual na Escola, sob a direção geral de Alexandre Bortolini.

Link para acessar o vídeo: https://www.youtube.com/watch?v=b2i5lRch_sc 
Todas/os as/os estudantes: Silêncio.

Professora pesquisadora: Ou ninguém entendeu nada, pessoal!

Alexia (parda, 15 anos): Achei que teve preconceito.

Professora pesquisadora: Preconceito do que?

Maria (branca, 15 anos): Preconceito contra os garotos que se beijaram.

Professora pesquisadora: Concordam com a colega?

Estudantes: Ahaaam.

Professora pesquisadora: Mas e daí, preconceito contra o beijo dos garotos...

Roger (pardo, 16 anos): Na verdade foi errado da parte dela, porque se não pode pra menina e menino, também não pode menino com menino, não importa se é homem com mulher ou homem com homem, já começa da escola.

Professora pesquisadora: Ah, muito bem. Susi o que achou do vídeo?

Susi (negra, 15 anos): $\quad$ Ah, eu achei tipo pô, preconceituoso. Porque tipo, eles não vão contra homem e mulher. Mas se chegar dois homens, assim se beijando já tem umas mil pessoas pra julgar isso, e tipo, achei muito errado da parte dela, da inspetora. Porque, tipo, todo mundo, não importa o sexo, todos somos iguais, apesar da cor, do gênero. (ENTREVISTA de GRUPO FOCAL, TEMA SEXUALIDADE, 23/06/16).

O silenciamento das/os participantes em relação ao vídeo pode indicar receio em discutir, no ambiente escolar, questões relacionadas à sexualidade. Considerando que a escola defende maneiras únicas de "ser" ou "jeitos de viver" a sexualidade e o gênero (LOURO, 2000) nesse ambiente. Também foi possível perceber que palavras como "heterossexualidade", "homossexualidade", "gay", "homofobia" não foram mencionadas no discurso das/os participantes no início das discussões, após a exibição do vídeo. Todavia, após a professora pesquisadora começar a mencionar as palavras "homossexual", "gay" e "heterossexual", as/os participantes da pesquisa também passaram a utilizá-las nas discussões seguintes. Ficou evidente que "o modo como alunos e professores se posicionam e são posicionados no discurso em relação a essas faces da identidade social tem repercussões na maneira como os alunos se posicionam nos discursos fora da sala de aula" (MOITA LOPES, 2002, p. 192). Por isso, se faz necessário um currículo de relevância social, que proporcione momentos de discussão e de questionamento das identidades, que sejam incluídas e tratadas com dignidade neste espaço.

Quanto ao discurso utilizado pela participante Susi, no final ela menciona: "Mas se chegar dois homens, assim se beijando já tem umas mil pessoas pra julgar isso, e tipo, achei muito errado da parte dela, da inspetora. Porque, tipo, todo mundo, não importa o sexo, todos somos iguais, apesar da cor, do gênero", revela o grande preconceito existente contra as identidades homossexuais, principalmente em relação à cor e ao gênero. Quando ela utiliza a palavra "mil" para especificar a quantidade de pessoas que julgariam um beijo entre dois homens, ela está chamando atenção para a forma preconceituosa, com que as pessoas julgam 
a homossexualidade como "pervertida", "anormal", "desviante" (LOURO, 2000). Assim como também, ao mencionar "todo mundo, não importa o sexo, todos somos iguais, apesar da cor, do gênero", revela a busca pela igualdade entre as diferentes formas de sexualidade, mas quando ela utiliza a palavra "apesar" e, em seguida, "cor e gênero", nos possibilita a pensar em uma suposta decepção em relação, primeiramente, à "raça”, depois em relação ao "gênero", como se houvesse algo errado, que teria que ser relevado, tolerado. E a tentativa de usar o discurso "somos todos iguais" para minimizar ofensas sofridas contra a sexualidade homossexual demonstra que, nas práticas sociais, não somos construídas/os de maneira iguais (MELO, 2015).

Assim, a partir dos vídeos, é possível oferecer possibilidades de realizar aulas interdisciplinares, nas quais a língua inglesa pode colaborar na (re)construção de significados no mundo em que vivemos, tanto local quanto global, possibilitando, ao mesmo tempo, adquirir a proficiência na língua e se (re)construir a si mesmas/os e as/os demais colegas que se encontram neste mesmo ambiente.

\section{SUGESTÕES DE ATIVIDADES}

\section{Vídeo: "Vista minha Pele"}

Link https://www.youtube.com/watch?v=LWBodKwuHCM

\section{Parte 1 - Discussões em grupos}

1.1-Qual é o significado da palavra racismo?

1.2- O que você pensa sobre o título do vídeo: "Vista a minha Pele"? Por quê?

1.3- No vídeo: "Vista a minha Pele", qual das personagens representam o padrão de beleza? Por que? E na vida real, qual é a representação de beleza? Por quê?

1.4 - O que mais lhe chamou atenção no vídeo: "Vista a minha Pele"? Por que?

1.5- No Brasil, "somos todas/os iguais" perante as questões raciais/cor? Existem diferenças? Quais?

\section{Parte 2 - Atividades}

2.1 Escreva a tradução dos seguintes adjetivos;
a) tall.
b) short.
c) happy.
d) sad.
e) angry
f) nervous
g) bored.
h) shy........

2.2 Faça uma pesquisa na sua família sobre seus ancestrais, desenhando a sua árvore genealógica familiar. 
2.4 Agora, escreva sentenças em inglês, utilizando os membros da família da atividade 2.2 e os adjetivos do exercício 2.1. Ex: My father is tall.

\section{Parte 3 - Trocando experiências}

3.1 A história apresentada no vídeo: "Vista minha Pele" ocorreu em que lugar?

3.2 Você já presenciou, ou passou por situações de racismo na escola? Descreva.

3.3 Agora, as narrativas elaboradas na atividade 3.2 serão expostas, e você terá que ler algumas. Após a leitura liste alguns sentimentos descritos nas narrativas causado pelo racismo.

3.4 Discuta com suas/seus colegas sobre os sentimentos descritos nas narrativas causado pelo racismo da atividade 3.3 .

3.5 Cite algumas sugestões a serem realizadas na sua escola para acabar com o racismo.

\section{Vídeo: “Acorda Raimundo”}

Link https://www.youtube.com/watch?v=HvQaqcYQyxU

\section{Parte 1 - Discussões em GRUPoS}

1.1 Qual é o significado da palavra estereótipo?

1.2- O que você pensa sobre o título do vídeo: "Acorda Raimundo"? Por quê?

1.3- O que mais lhe chamou atenção no vídeo: "Acorda Raimundo"? Por quê?

1.4- No vídeo: "Acorda Raimundo", qual das personagens representam o padrão de feminilidade e de masculinidade? Por quê? E na vida real, qual é a representação de feminilidade e de masculinidade? Por quê?

1.5-Você acha que no Brasil, "somos todas/os iguais", independente de sermos mulheres ou homens? Existem diferenças? Quais?

\section{Parte 2 - Atividades}

2.1 Complete as sentenças, conforme exibido no vídeo (Marta e/ou Raimundo), circulando a forma correta dos verbos no presente.

\begin{tabular}{|c|c|}
\hline 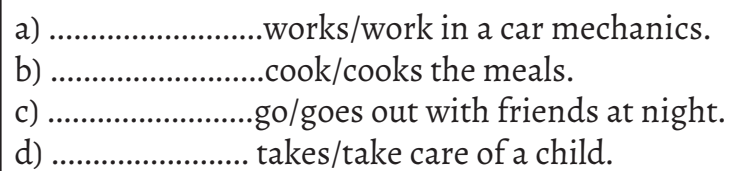 & $\begin{array}{l}\text { e) ..................wash/washes the clothes. } \\
\text { f) ..................spends/spend the money. } \\
\text { g) ..............wash/washes the clothes. }\end{array}$ \\
\hline
\end{tabular}


2.2 Observe as sentenças do exercício 2.1 e discuta os tipos de trabalhos realizados pela Marta e pelo Raimundo exibidos no vídeo: “Acorda Raimundo" - há necessidade de separar obrigatoriamente os trabalhos: para "mulheres" e para "homens"? Por quê?

2.3 Conforme apareceu no vídeo: "Acorda Raimundo" comente sobre a violência doméstica: $\mathrm{O}$ que é violência doméstica? Onde acontece? Quais os tipos de violência doméstica mais recorrentes? Por que acontece a violência doméstica? Discuta com suas/seus colegas.

2.4 Você já presenciou tal situação? Como ocorreu? Comente com suas/seus colegas.

2.5 Quais as atitudes devem ser tomadas em relação a violência doméstica?

\section{Parte 3 - Trocando experiências}

3.1 Você já ouviu expressões do tipo "isto é coisa de menina”, "isto é coisa de menino”, ou qualquer outra expressão parecida, no momento em que você queria fazer algo? Descreva o episódio.

3.2 O que você pensa sobre; "coisas para mulheres", e "coisas para homens"? Justifique.

3.3 Como você imagina uma sociedade igualitária para mulheres e homens?

3.4 Converse com colegas da sua classe, e escreva algumas atitudes machistas presentes na sua escola/sala de aula, em seguida apresente sugestões para superar cada uma destas atitudes machistas.

Vídeo: "Novamente Homofobia na Escola"

Link https://www.youtube.com/watch?v=b2i5lRch_sc

\section{Parte 1 - Discussões em GRUPos}

1.1- Qual é o significado da palavra homofobia?

1.2- O que você pensa sobre o título do vídeo: "Novamente homofobia na escola"? Por quê?

1.3- O que mais lhe chamou atenção no vídeo:” Novamente homofobia na escola"? Por quê?

1.4- O vídeo: "Novamente homofobia na escola" tem semelhança com a vida real? Por quê?

1.5-Você acha que no Brasil, a expressão "somos todas/os iguais", se aplica as pessoas homossexuais? Por quê? Existem diferenças? Quais?

\section{Parte 2-Atividades}

2.1 Escreva em inglês, os seguintes artigos da Declaração Universal dos Direitos Humanos: 
Artigo $\mathbf{1}^{\circ}$ - Todos os seres humanos nascem livres e iguais em dignidade e em direitos. Dotados de razão e de consciência, devem agir uns para com os outros em espírito de fraternidade.

Artigo $3^{\circ}$ - Todo indivíduo tem direito à vida, à liberdade e à segurança pessoal.

Artigo $7^{\circ}$ - Todos são iguais perante a lei e, sem distinção, têm direito a igual proteção da lei. Todos têm direito a proteção igual contra qualquer discriminação que viole a presente Declaração e contra qualquer incitamento a tal discriminação.

http://www.ohchr.org/EN/UDHR/Documents/UDHR_Translations/por.pdf

2.2 Complete as sentenças com o verbo "have" no presente simples;

a) We ................ the right to quality education.

b) They ........... the right to equality regardless of their sexuality, religion and skin color.

c) She ........... the right to be respected in her dignity in the school environment, regardless of her sexual orientation.

d) I ............the right to be respected for being who I am.

e) He .............. the right to be respected for his sexual orientation.

\section{Parte 3 - Trocando eXPeriênCIAS}

3.1 Você já presenciou/ soube de alguma situação de preconceito pela orientação sexual de alguém? Descreva como ocorreu.

3.3 Agora, as narrativas elaboradas na atividade 3.1 serão expostas e você terá que ler algumas. Após a leitura liste alguns sentimentos que a homofobia causou na vítima. Em seguida comente com suas/seus colegas sobre as consequências da homofobia.

3.4 No ambiente escolar como é tratado as questões referentes a orientação sexual?

3.5 Apresente algumas sugestões de como você gostaria que a escola trabalhasse com as questões referentes a orientação sexual.

3.5 Escreva em inglês, uma frase contra a homofobia e ilustre-a. Em seguida deixe-a em exposição para toda a turma.

\section{CONSIDERAÇÕES FINAIS}

Considerando a proposta deste artigo de responder às seguintes perguntas de pesquisa: como a Língua Inglesa pode ser utilizada como instrumento de questionamento para as práticas sociais? E, que tipo de atividades podem ser inseridas, nas aulas de Língua Inglesa, que possam oportunizar a (des)construção das identidades de raça, gênero e de sexualidade? Concluo, perante as análises realizadas, que a Língua Inglesa pode ser utilizada como instrumento de questionamento para as práticas sociais quando o espaço das aulas de Língua Inglesa possibilita discussões, reflexões e oportuniza discursos menos aprisionadores sobre 
as questões de gênero, de raça e de sexualidade, possibilitando relações entre o local e o global, como um espaço de resistência e de mudança no que causa dor e sofrimento a corpos deslegitimados, os quais podem encontrar apoio importante, em que ao mesmo tempo possam a desenvolver a proficiência na língua inglesa, e também aprender a se defender da violência, atribuídas/os a elas/eles pelo fato de terem assumido viver suas identidades.

Dessa forma, as atividades devem ser programadas considerando e oportunizando a (des)construção das identidades de raça, gênero e de sexualidade, onde haja a superação de aulas conteudistas, as quais objetivam apenas o ensino/aprendizagem da língua somente como código. Pois ao desenvolver atividades em que as/os estudantes possam (re)ver, (re) pensar e se colocar no lugar das demais pessoas, é possível despertar o lado humano de cada uma/um que esteja inserida/o na sala de aula naquele momento, (trans)formando-as/os em pessoas mais sensíveis e humanas para a solidariedade para com o semelhante. Oportunizando aprender e desenvolver valores, crenças, hábitos, respeito, acolhida e (con)vivência em que possibilite a desfazer-se de certas opiniões estigmatizantes, violentas, racistas, preconceituosas, machistas, homofóbicas sobre corpos, cabelos, mulheres, negras/os, masculinidades, feminilidades, na convivência diária com as pessoas, tanto na sala de aula como em qualquer outro lugar da sociedade.

Desse modo, compreender como a Língua Inglesa pode ser usada para o empoderamento das identidades no ambiente escolar é significativo para desconstruir hierarquizações de poder existentes. Para isso, se torna importante considerar a formação continuada de professoras/es, a criticidade ao selecionar os materiais didáticos, os quais transmitem e agem diretamente no currículo oculto passando mensagens as/aos estudantes, ter consciência do discurso utilizado ao se referir tanto as/os estudantes como às demais pessoas que fazem parte da escola, sejam as/os profissionais ou membros da comunidade escolar, procurando sempre tornar a escola um ambiente acolhedor para todas as pessoas que dela se aproximem, onde se sintam respeitadas e seguras na sua dignidade de ser humano, independente da orientação sexual, da raça e do gênero. Pois provavelmente um dos maiores desafios de nossos dias seja construir uma forma de produzir conhecimento que possibilite criar alternativas sociais para aquelas/es que sofrem às margens da sociedade.

\section{REFERÊNCIAS}

BEAUVOIR, S. O Segundo Sexo, fatos e mitos. Tradução de Sérgio Milliet. Edição 4, Difusão Européia do livro, 1970.

BUTLER, J. Problemas de Gênero: Feminismo e Subversão da Identidade. Rio de Janeiro: Civilização Brasileira, 2010.

FERREIRA, A. de J. Identidades Sociais de Raça/Etnia na Sala de Aula de Língua Inglesa. In: FERREIRA, A. de J. (Org.). Identidades Sociais de Raça, Etnia, Gênero e Sexualidade: Práticas 
Pedagógicas em Sala de Aula de Línguas e Formação de Professores/as. Campinas, SP: Pontes Editora, 2012, p. 19 - 50.

FERREIRA, A. de J. Narrativas Autobiográficas de Professoras/es de Línguas na Universidade: Letramento Racial Crítico e Teoria Racial Crítica. In: FERREIRA, A. de J. (Org.). Narrativas Autobiográficas de Identidades Sociais de Raça, Gênero, Sexualidade e Classe em Estudos da Linguagem. Campinas, SP: Pontes Editores, 2015, p. 127-159.

FURLANI, J. Encarar o Desafio da Educação Sexual na Escola. Paraná. Secretaria de Estado da Educação. Superintendência de Educação. Departamento da Diversidade. Núcleo de Gênero e Diversidade Sexual. Curitiba: SEED- Pr, 2009, p. 37-48.

GARCIA, C. C. Breve História do Feminismo. São Paulo: Claridade, 2011.

GOMES, N. L. Alguns Termos Presentes no Debate sobre Relações Raciais no Brasil: uma Breve Discussão. Secretária de Educação Continuada, Alfabetização e Diversidade. Brasília. Educação anti-racista: caminhos abertos pela Lei Federal n.10.639/03. Ministério da Educação, Secretaria de Educação Continuada, Alfabetização e Diversidade, 2005, p. 39-62.

LOURO, G. L. Gênero, Sexualidade e Educação. Uma perspectiva Pós-Estruturalista. Petrópolis, RJ: Vozes, 1997.

LOURO, G. L. Pedagogias da Sexualidade. In: LOURO, G. L. O corpo educado, pedagogias da sexualidade. 2. Ed.. Belo Horizonte: Editora Autêntica, 2000, p. 07-26.

LOURO, G. L. Currículo, Gênero e Sexualidade: o "normal", o "diferente" e o "excêntrico". In: LOURO, G. L; FELIPE, J.; GOELLNER, S. V. (Orgs.). Corpo, Gênero e Sexualidade: um Debate Contemporâneo na Educação. 9. Ed.. Petrópolis, RJ: Vozes, 2013.

MELO, G. C. V. O Lugar da Raça na Sala de Aula de Inglês. Revista da ABPN. v. 7, n. 17, julhooutubro, 2015, p. 65-81.

MOITA LOPES, L. P. da. Identidades Fragmentadas: a Construção Discursiva de Raça, Gênero e Sexualidade em Sala de Aula. Campinas. S.P: Mercado das Letras, 2002.

MOITA LOPES, L. P. Socioconstrucionismo: Discurso e Identidade Social. In: MOITA LOPES, L. P. (Org.) Discursos de Identidades: discurso como espaço de construção de gênero, sexualidade, raça, idade e profissão na escola e na família. Campinas, SP: Mercado de Letras, 2003.

MOITA LOPES, L. P. Linguística aplicada e vida contemporânea: problematização dos construtos que têm orientado a pesquisa. In: MOITA LOPES, L. P. (Org.). Por uma Linguística INdiciplinar. Parábola Editorial, 2006, p. 85-107.

MOITA LOPES, L. P. Linguagem e escola na construção de quem somos. In: FERREIRA, A. de J. (Org.). Identidades sociais de raça, etnia, e sexualidade - práticas pedagógicas em sala de aula de línguas e formação de professores/as. Campinas, SP. Pontes Editores, 2012.

PENNYCOOK, A. Uma Linguística aplicada transgressiva. In: MOITA LOPES, L. P. da. (Org.) Por uma Línguística Aplicada INdisciplinar. São Paulo: Parábola Editorial, 2006, p. 67-83. 
PINTO, J. P. Gênero e suas Articulações para Igualdade e Pluralidade na Educação Linguística. In: FERREIRA, A. de J.; JOVINO, I. da S.; SALEH, Pascoalina B. de O. (Orgs.) Um Olhar Interdisciplinar Acerca de Identidades Sociais de Raça, Gênero e Sexualidade. Campinas, SP: Pontes Editores, 2014, p. 103-122.

SENE, R. A. R. de. Identidades de raça, de gênero e de sexualidade nas aulas de língua inglesa na visão das/os estudantes. Ponta Grossa. 2017. Dissertação Mestrado, 200F.

Recebido para publicação em 14 de Janeiro de 2020. Aceito para publicação em 6 de Março de 2020. 